\title{
The Role of Child Studies for Child-Related Laws and Policies
}

\author{
Songyon $\mathrm{Cho}^{1}$, Eun Bae Khil ${ }^{2}$, Hye Yeong $\mathrm{Choi}^{3}$ \\ Department of Early Childhood Education, Hoseo University, Cheonan, Korea ${ }^{1}$ \\ Department of Youth Guidance \& Sport Education, Korea National Sport University, Seoul, Korea ${ }^{2}$ \\ Department of Family Welfare, Changwon National University, Changwon, Korea ${ }^{3}$
}

아동관련법과 정책에 대한 아동학의 역할

조성연 ${ }^{1}$, 길은배 ${ }^{2}$, 최혜영 ${ }^{3}$

호서대학교 유아교육과 ${ }^{1}$, 한국체육대학교 스포츠청소년지도학과 ${ }^{2}$, 창원대학교 가족복지학과 ${ }^{3}$

Objective: The purpose of this study was to understand the role of specialists in child studies by analyzing child-related laws and policies and their service systems.

Methods: We analyzed the aims, background, history, and related 5-year-plans in child-related laws and policies and their service delivery systems.

Results: There were many difficulties in enforcing consistent policies. First, there was no unified age for implementing child and youth policy. Second, there was no comprehensive long-term policy. Third, many departments were involved.

Conclusion: The study findings suggest the future role of specialists in child studies. First, they must take steps to introduce a monitoring system for the proper implementation of the first master plan for child policy. Second, they need to put effort into improving treatment of child-related workers. Third, they have to expand the academic area of child studies by reforming university curricula in a more pragmatic way. Fourth, the procedure to acquire different certifications in child studies and youth studies needs to be affiliated.

Keywords: child studies, child-related laws, child-related policies$$
\text { 서론 }
$$

한 나라의 미래는 그 나라의 아동이 얼마나 안전하고 행복하 게 성장하느냐와 밀접한 관련이 있다. 이를 위해 국가마다 아 동을 위한 다양한 정책과 제도를 마련하여 시행하고 있다. 이 런 점에서 우리나라 아동을 위한 정책과 제도의 마련과 실시 는 그리 밝지만은 않다. 우리나라 아동의 삶의 만족도와 주관 적 행복도지수가 낮고(Korean Foundation of Banjeongwhan \&

Corresponding Author: Hye Yeong Choi, Department of Family Welfare, Changwon National University, 20 Changwondaehak-ro Uichang-gu Changwon-si, Gyeongsangnam-do, Korea

E-mail: flora@changwon.ac.kr
\end{abstract}

Institute for Social Development Studies. 2016; The Organisation for Economic Co-operation and Development [OECD], 2015), 기혼여성의 경제활동참가율도 매년 증가하고 있어 아동의 양 육환경도 급격하게 변화하고 있다. 이러한 점을 고려해볼 때 정부는 아동을 위해 보다 적극적인 사회적 투자전략을 모색할 필요가 있다.

한편, 아동을 둘러싼 환경은 다양한 위험에 처해있다. 최근 모든 영유아(0-5세)를 대상으로 실시하고 있는 무상보육정책

C.The Korean Association of Child Studies

This is an Open Access article distributed under the terms of the Creative Commons Attribution Non-Commercial License (http:// creativecommons.org/licenses/by-nc/4.0) which permits unrestricted noncommercial use, distribution, and reproduction in any medium, provided the original work is properly cited. 
은 부모의 양육 지원 취지는 살렸으나 자녀와 부모가 오랜 시 간 분리되고 각종 안전사고와 학대 위험에 노출되는 등의 문 제점을 안고 있다. 그 외에도 학교폭력 피해 증가, 사교육 심화 로 인한 스트레스 증가 등의 교육환경에서 나타난 문제는 아 동기의 성장.발달에 심각한 위협요인으로 작용하고 있다. 뿐 만 아니라 최근에는 스마트폰의 급속한 보급과 활용으로 아동 의 중독문제와 생활습관형 질병의 증가도 아동의 신체적, 정 신적 건강을 저해하는 주요 요인이 되고 있어 이의 예방을 위 한 정부차원의 노력도 시급하다.

아동에 대한 지원과 환경의 개선을 위해서는 일관성 있는 법제정과 정책 시행이 필수적이다. 그러나 정부가 바뀔 때마 다 아동관련 정책은 늘 주요 대상이 되지 못하였고, 아동관 련 업무 소관 부처도 변경되거나 양분되는 등 정책 시행이 연 계되지 못하여 일관성 없이 실시되어 왔다. 1961년 아동복리 법 제정 시 아동관련 업무는 보건사회부가 담당하였고, 아동 과 연령이 중복되는 청소년 업무는 아동관련 업무와 별개로 1987년 청소년육성법을 제정하면서 당시 체육부에서 담당하 였으나 체육부가 문화관광부로 통합되면서 청소년 업무도 함 께 이관되었다(Hwang, 2010). 이후 청소년관련 업무는 다양 한 부처에서 관장하였고, 2010년 공포된 정부조직법에 따라 영-유아보육을 포함한 아동에 관한 업무는 보건복지부에서, 청소년 및 가족 관련 업무는 여성가족부가 관장하도록 양분되 었다.

현재 아동관련 업무는 현행 법제에 나타난 아동 연령을 기 준으로 실시하고 있다. 즉, 아동은 아동복지법(Child Welfare Act [CWA], Act No. 14058, 2016)을 근간으로 "18세 미만의 자" 로, 청소년은 청소년 기본법(Framework on Juveniles, Act No. $14066,2016)$ 에 의해 "9-24세 이하인 자"로, 청소년 보호법 (Juveniles Protect Act, Act No. 13726, 2016)에 의해서는 "19세 미만의 자”로 규정하여 관련 정책을 입안하여 실시하고 있다. 관련 법제에서 드러난 바와 같이 연령이 중복됨에도 불구하고 우리나라 아동정책은 청소년정책과 별개로 입안하여 운영하 고 있어 정책 실행에 혼선을 빚고 있다. 그에 따라 아동학의 입 장에서는 연구와 정책 입안의 범위와 역할 등에 상당한 혼란 을 초래할 수 있고, 심지어 아동학자로서의 역할에 대한 정체 성마저 혼란스럽게 할 수도 있다. 그 이유는 아동학은 18세 미 만의 아동만을 대상으로 연구하는 것이 아니라 청소년의 연령 범위도 포괄하고 있고, 심지어 생애주기적인 관점에서의 연구 도 활발하게 진행하고 있기 때문이다. 따라서 다소 늦은 감은 있으나 아동학에서 아동에 대한 연구와 정책 입안 및 실행을 위한 기초 작업으로 아동학이 어떻게 조화로운 역할을 수행할
수 있는지에 대해 생각해볼 필요가 있다. 이를 위해 청소년을 포함하는 아동 대상의 모든 법령을 살펴보기에는 무리가 있어 본 고에서는 아동과 청소년관련 기본 법령을 중심으로 그에 따른 기본 정책과 전달체계를 살펴봄으로써 아동학이 어떤 역 할을 수행해야 할지에 대해 생각해보고자 한다. 이러한 고찰 을 통해 향후 아동학의 정체성 확립과 아동관련 정책의 입안 과 실행을 위한 기초자료로 활용할 수 있을 것이다.

\section{아동관련법의 제정 배경과 목적}

본 고에서는 우리나라의 아동과 청소년 관련 정책 입안의 근 간이 되는 법령을 중심으로 아동관련법을 선정하여 살펴보 고자 한다. 이를 위해 아동복지법, 영유아보육법(Infant Care Act ICA]), 아동학대범죄의 처벌 등에 관한 특례법(Act on special cases concerning the Punishment of Child Abuse Crimes [APCAC]), 아동의 빈곤예방 및 지원 등에 관한 법률(Act on Prevention of Child Poverty, support of children [APCP]), 실종 아동 등의 보호 및 지원에 관한 법률(Act on the protection and support of Missing Children [AMC], 청소년 기본법, 청소년활 동 진흥법(Juvenile Activity Promotion Act [JAPA]), 청소년복지 지원법(Juvenile Welfare Support Act [JWSA]) 등을 선정하여 그 목적과 주요 내용 등을 중심으로 살펴보았다.

첫째, 아동복지법은 아동을 “18세 미만의 자"로 규정하고 아동이 건강하게 출생하여 행복하고 안전하게 자랄 수 있도 록 아동의 복지를 보장하는 것을 목적으로 한다(CWA, Act No. $14058,2016)$. 이를 위해 동법은 아동이 행복한 삶을 누릴 수 있는 기본적인 여건을 조성하고 조화롭게 성장.발달할 수 있 도록 경제적·사회적·정서적으로 지원해주고자 한다. 특히 동 법은 최근의 아동학대 문제가 심각한 사회문제로 등장하면서 아동학대와 관련한 내용을 강화하여 아동의 보호 주체와 아동 의 복지를 위한 서비스 및 주요 시설 등에 대한 내용을 담고 있 다. 즉, 동법은 아동의 복지증진 및 보호책임의 주체를 국가와 지방자치단체, 보호자 및 국민으로 명시함으로써 5년마다 아 동정책기본계획 수립 및 아동의 종합실태 조사를 실시하고, 보호자와 모든 국민이 아동의 권익과 안전을 존중하여 아동을 건강하게 양육하도록 명시하고 있다. 또한, 동법은 아동보호 서비스와 아동의 최상의 이익을 위한 보호조치 시행 및 이에 필요한 정보 관리와 매년 보호대상아동의 양육 상황 점검과 아동학대 예방과 방지를 위한 각종 정책의 수립 및 시행과 실 태조사, 신고체제 운영 및 지원, 아동학대에 대한 긴급전화 설 
치 등을 명시하고 있다. 이와 더불어 동법은 아동 안전 및 건강 지원과 취약계층 아동의 통합서비스지원 및 자립지원 명시 및 아동보호구역 지정과 취약한 가정을 위한 통합서비스 실시, 보호대상아동의 보호와 자립지원 시행, 각종 아동복지시설과 아동전용시설 설치를 위해 노력할 것을 명시하고 있다.

둘째, 영유아보육법은 영유아의 심신 보호와 교육을 통한 건강한 사회 구성원으로의 육성과 보호자의 경제적-사회적 활동 지원을 통한 영유아 및 가정의 복지 증진에 이바지함을 목적으로 한다(ICA, Act No. 14001, 2016). 동법은 보육정책조 정위원회와 육아종합지원센터 및 보육개발원의 설치를 명시 하였고, 3 년마다 보육실태조사의 실시 및 어린이집 설치와 운 영, 교직원의 자격과 관리감독의 근거를 마련한 내용을 포함 하고 있다.

셋째, 아동학대범죄의 처벌 등에 관한 특례법(약칭: 아동 학대처벌법)은 아동학대범죄의 처벌 및 그 절차에 관한 특례 와 피해아동에 대한 보호 절차 및 아동학대행위자에 대한 보 호처분을 규정함으로써 아동을 보호하여 아동이 건강한 사회 구성원으로 성장하도록 함을 목적으로 한다(APCAC, Act No. $14172,2016)$. 동법은 아동학대범죄가 발생한 경우 긴급한 조 치 및 보호가 가능하도록 제도를 마련하여 아동학대에 대한 강력한 대처와 예방을 할 수 있도록 아동학대치사죄 및 아동 학대중상해죄를 신설하여 최고 무기징역에 처하도록 아동학 대범죄에 대한 처벌규정을 강화하고, 상습범 및 아동복지시설 종사자 등에 대해서는 가중처벌 하도록 하였다. 또한, 아동복 지시설 종사자 등의 아동학대범죄에 대한 신고를 의무화하였 고, 학대사례에 대한 수사기관과 검사 법원의 역할을 강조하 여 중대 사건과 유사하게 처리할 수 있도록 하였다.

넷째, 아동의 빈곤예방 및 지원 등에 관한 법률(약칭: 아동 빈곤예방법)은 생활여건과 자원의 결핍으로 인한 빈곤아동이 소외와 차별 없이 사회의 구성원으로서 건강하게 자랄 수 있 도록 제도적 기반 마련을 목적으로 한다. 동법은 빈곤아동을 돕기 위한 재원 확보와 실태조사를 통한 정책 수립 및 시행, 전 달체계 구축 및 제도 개선, 5 년마다 기본계획을 수립하도록 명 시하고 있다(APCP, Act No. 12844, 2014).

다섯째, 실종아동 등의 보호 및 지원에 관한 법률(약칭: 실 종아동법)은 실종아동 등의 발생을 예방하고 조속한 발견과 복귀를 도모하며 복귀 후의 사회 적응을 지원함으로써 실종 아동 등과 가정의 복지증진에 이바지함을 목적으로 한다. 동 법은 실종아동에 대한 것을 국가의 책무로 규정하여 보건복 지부장관과 경찰청장의 책무를 담고 있는데 이를 위해 실종아 동 등을 위한 정책수립과 실태조사 및 연구, 가족지원 시행, 신
고체계의 구축·운영, 수색 및 수사 등을 시행하도록 하고 있다 (AMC, Act No. 12844, 2014).

여섯째, 청소년 기본법은 청소년의 권리 및 책임과 가 정 - 사회 · 국가. 지방자치단체의 청소년에 대한 책임을 정하 고 청소년정책에 관한 기본적인 사항을 규정함을 목적으로 한 다. 동법은 청소년이란 용어를 정의하고, 청소년육성에 관한 기본계획의 수립 및 청소년정책의 조정에 관한 사항 등의 심 의·조정, 국가자격인 청소년지도사와 청소년상담사 양성에 관한 사항, 청소년육성전담공무원제도의 명시, 청소년육성기 금 설치를 통해 청소년육성에 필요한 재원 확보 근거를 담고 있다(FJA, Act No. 14066, 2016).

일곱째, 청소년활동 진흥법은 청소년활동을 적극적으로 진 흥하기 위하여 필요한 사항을 정함을 목적으로 한다. 동법은 청소년수련시설의 운영과정에 대한 청소년의 참여를 보장하 기 위한 청소년운영위원회의 설치 및 운영, 청소년활동정책 시행과 지원을 위한 한국청소년활동진흥원의 설치 및 운영, 청소년활동시설의 명기와 청소년수련활동인증제도의 운영 등을 명시하고 있다(JAPA, Act No. 14068, 2016).

여덟째, 청소년복지 지원법은 9세 이상 18 세 이하의 청소 년을 대상으로 청소년복지 향상에 관한 사항을 규정함을 목적 으로 한다. 동법은 청소년증 발급, 지역사회 청소년통합지원 체계(CYS-Net)의 구축·운영에 관한 사항, 청소년복지시설의 운영과 지원, 한국청소년상담복지개발원의 설치와 운영 등에 대한 내용을 담고 있다(JWSA, Act No. 14237, 2016).

\section{아동관련법과 정책}

\section{아동관련법과 정책의 변천과정}

국가적 차원의 아동관련 정책은 아동과 청소년을 나누어 소관 부처에서 관련 종합대책을 입안하여 실시해왔다. 이를 연대별 로 살펴보면 다음과 같다.

첫째 시기는 해방 이후부터 1960 년으로, 이 시기는 아동과 청소년을 분리하지 않고 한국전쟁으로 인한 고아, 기아, 부랑 아 문제 해결을 위한 복지서비스를 위한 1946년 아동노동법 규의 제정과 해외 원조에 의존한 아동복지서비스가 제공되었 으며, 1957년 어린이 헌장을 제정하여 발표하였다.

둘째 시기는 1961년부터 1980년으로, 아동정책 차원에서 는 해외원조가 감소함에 따라 국가적 차원의 지원이 필요하 게 되어 1961년에 아동복리법을 제정하여 요보호 아동에 대 
한 선별적 차원의 공적 지원을 실시하였고, 1967 년에는 탁아 시설 설치 5 개년 계획을 발표하였다. 한편, 청소년정책 차원에 서는 1961년에 미성년자보호법이 제정되었고, 문제청소년 중 심의 보호대책을 위해 1964년 청소년보호대책위원회를 설치 한 후 일반청소년 보호대책으로 확대하고자 1977년 청소년대 책위원회로 명칭을 변경하여 운영하였다.

셋째 시기는 1981년부터 1999년으로, 다양한 아동과 청소 년관련법이 제정되어 시행되었다. 아동관련법으로는 아동복 리법을 1981년에 아동복지법으로 개정하였고, 1982년에 유 아교육진흥법, 1991년에 영유아보육법 등이 제정되어 시행 되면서 일반아동에 대한 보편적 복지로 확대되었고, 처음으 로 1994년에 보육시설 확충 3개년 계획이 발표되었다. 한편, 청소년관련법으로는 1987년에 청소년육성법, 1991년에 청 소년기본법, 1997년에 청소년보호법 등이 제정되어 시행되 었으며, 1990년에 청소년헌장을 제정하여 공포하였다. 청소 년정책은 아동정책에 비해 보다 활발하게 이루어져 1991년 에 한국청소년기본계획, 1993 년에 제 1 차 청소년육성 5 개년계 획, 1998년에 제2차 청소년육성 5개년계획 등이 수립되었고, 1998 년에 시대에 맞게 청소년헌장을 개정하였으며, 1997년에 청소년문제를 중점적으로 다룰 수 있도록 문화관광부에 청소 년보호위원회를 설치, 운영하였다. 이 시기에 청소년을 위해 서는 다양한 수련시설을 건립하고, 전문지도자 양성을 위한 청소년지도자 제도를 마련하였다.

넷째 시기는 2000년부터 현재로, 아동과 청소년 문제가 주 요 이슈가 되면서 다양한 법이 제정되어 시행되었다. 아동관 련법으로는 2004년에 영유아보육법과 2012년에 아동복지법 이 전면 개정되었고, 2014년에 아동학대처벌법이 제정되었 다. 아동정책과 관련해서는 2002년에 어린이보호육성종합대 책, 2003년에 어린이안전종합대책, 2004년에 빈곤아동청소 년종합대책, 2008년에 아동청소년정책 5개년 기본계획, 2015 년에 아동정책기본계획 등이 수립되어 아동권리와 학대아동 보호 및 안전에 대한 지원을 확대하였다. 한편, 청소년관련법 으로는 2000년에 아동청소년 성보호에 관한 법률, 2004년에 청소년활동진흥법과 청소년복지지원법, 2014년에 학교밖 청 소년지원에 관한 법이 제정되었고, 그에 따라 2003년에 제3 차 청소년육성기본계획, 2008년 제4차 청소년정책기본계획, 2013년 제5차 청소년정책기본계획이 수립되었으며, 2005년 에는 국가청소년위원회가 출범하였다. 그러나 2008년 청소년 정책은 보건복지가족부에서 시행했으나 2010년 여성가족부 로 이관되었다.

이러한 시대별 변천을 통해 알 수 있듯이 아동관련법은
청소년관련법에 비해 더 우선적으로 제정되었으나 그 정책 이나 실행기관은 청소년이 먼저 이루어졌다. 청소년정책 은 청소년 기본법에 근거하여 5년 주기의 기본계획을 수립 하여 실행해왔으나 아동정책은 2015년에 와서야 처음으로 기본계획을 수립하여 실행하고 있다. 또한, 정책 실행을 위 한 주무부처도 아동은 보건복지부, 청소년은 여성가족부에 서 관장하고 있어 아동과 청소년정책은 여전히 통합되지 못한 채 이루어지고 있다.

\section{아동관련 기본계획}

아동관련 기본계획은 청소년을 포함하여 아동에 대한 정책과 관련 서비스의 시행을 위한 아동정책기본계획의 수립과 시행 에 대한 법적 근거는 아동복지법에 근거하고, 청소년에 대한 것은 청소년 기본법에 근거하여 이루어진다.

먼저 아동정책의 기본계획은 여러 관련 부처에서 산발적 으로 수행해왔던 아동관련 정책을 통합하여 포괄적이고 종합 적으로 실시하고자 2015년에 처음으로 수립되었다. 이는 우 리나라에 거주하는 18 세 미만의 모든 아동을 대상으로 하지 만 정책 과제에 따라 임산부 및 18 세 이상 청소년도 일부 포함 하며, 우리나라에 거주하는 외국 아동도 포함한다. 제1차 아 동정책기본계획은 2015-2019년의 5개년에 걸쳐 총 약 4.5조 원의 예산을 투입하여 “행복한 아동, 존중받는 아동”을 비전 으로 아동 행복도 증진과 아동 최우선의 원칙을 실현할 수 있 는 기반 조성을 핵심목표로 설정하였다(Ministry of Health and Welfare [MOHW], 2015). 이를 위해 이는 미래를 준비하는 삶, 건강한 삶, 안전한 삶, 함께하는 삶의 4 개 영역 및 기본계획 실 행기반 조성 등 총 5 개 부문에 걸쳐 16 개의 중점과제, 158 개의 세부과제 및 핵심지표를 제시하였다. 부문별 중점과제와 핵 심지표로 '미래를 준비하는 삶’은 아동기 역량 강화, 꿈과 끼를 살리는 교육 실현, 아동의 참여권 보장, 놀이.여가 권리 보장 으로 아동결핍수준(정기적 여가활동 결핍), 공동체 의식이고, '건강한 삶'은 생활공간 기반 건강관리체계 마련, 발달주기별 건강관리체계 내실화로 영유아 건강검진률, 신체활동 실천율, 15-19세 자살률(인구 10만명당)이다. '안전한 삶'은 생활안 전, 사회안전, 아동안전 체계 구축으로 안전사고 사망자수(아 동10만 명당), 아동범죄 피해자수(15세 이하), 재학대 판정률 이고, '함께하는 삶’은 아동보호 무차별 원칙 실현, 사회적 보 호-지원 필요아동에 대한 종합대책 마련 시행으로 빈곤아동 삶의 만족도, 소년범 재범률이다. '실행기반'은 아동권리 실현 기반 조성, 민간과의 협력 강화, 가정의 양육역량 강화, 아동정 
책지원 인프라 강화, 아동친화적 지역사회 조성이며, 기본계 획 전반의 핵심지표는 삶의 만족도, 행복지수(주관적 행복 영 역), $U N$ 아동권리협약 권고사항 이행률이다.

또한, 청소년정책의 기본계획은 1991 년에 제 1 차 청소년기 본계획이 수립된 이후 현재 제 5 차 기본계획이 발표되었고, 단 기적인 계획을 포함한다면 총 7회차의 계획을 수립하여 추진 해왔다. 현재 2013년에서 2017년까지 제5차 청소년정책기본 계획이 시행되고 있다. 현행 기본계획은 “청소년이 행복한 세 상, 청소년이 꿈꾸는 밝은 미래”를 비전으로 청소년의 역량 함 양 및 미래핵심인재 양성, 청소년의 자기주도적 참여와 권리 증진, 청소년의 균형 있고 조화로운 성장, 청소년의 안전하고 건강한 생활 환경을 목표로 설정하여 5 개 영역의 15 개 중점과 제와 75개 세부과제를 제시하였다(Ministry of Gender Equality and Family [MOGEF], 2012). 영역별 중점과제는 '청소년의 다 양한 역량 강화'는 청소년 역량증진 활동 활성화, 글로벌 - 다 문화 역량 강화, 청소년의 인성 및 민주시민 교육 강화에 16 개 세부과제가 있고, '청소년 참여 및 권리 증진'은 청소년의 참여 활성화, 청소년의 건강권 보호, 청소년의 권리증진 기반 조성 에 13 개 세부과제, '청소년 복지 및 자립 지원'은 대상별 맞춤 형 서비스 강화, 위기청소년 보호·지원 강화, 청소년(청년) 진 로체험 및 자립 지원에 22개 세부과제, '청소년 친화적 환경 조 성'은 건강한 가정 및 지역사회 조성, 안전한 생활환경 조성, 건전한 매체환경 조성 및 의식제고에 15 개 세부과제, '청소년 정책 추진체계 강화'는 범부처 정책 총괄.조정 기능 강화, 청 소년 지원 인프라 보강, 청소년정책 추진기반 강화에 9개 세부 과제를 제시하였다. 청소년기본계획의 주요 추진전략은 청소 년정책의 국가정책 우선순위 부여라는 선제적 정책, 청소년정
책의 총괄·조정 기능 강화라는 종합적 정책, 청소년의 다양한 이해와 요구를 포괄하는 지역사회 중심 정책, 청소년의 구체 적 대상별 맞춤형 접근을 필요로 하는 맞춤형 정책 추진, 과학 적인 근거에 입각한 과학적 정책 추진 등이다.

\section{아동관련정책의 전달체계}

\section{아동정책서비스 전달체계}

아동정책의 서비스 전달체계는 중앙정부에서 지방정부 그리 고 서비스 시행기관으로 이어지는데 2005년을 기점으로 대다 수의 사업이 지방정부로 이양되면서 지방정부의 결정권이 커 졌다. 단, 아동학대에 관련된 사업은 2015년에 다시 중앙정부 로 이관되었다. 아동관련 정책의 중앙부처는 보건복지부, 교 육부 등이고 문화체육관광부, 미래창조과학부 등이 협조체제 를 이루고 있다. 과거에 비해 아동을 위한 다양한 정책의 입안 과 실시에 있어 관련 부처가 차지하는 비중이 점차 증가하고 있다.

아동관련 정책은 보건복지부 장관을 수장으로 하여 인구 정책실의 인구아동정책관과 보육정책관을 중심으로 업무가 이루어지고 있다(Figure 1). 아동복지관련 사업은 각 시 · 도 및 시·군·구별 사회복지전담공무원과 민간 사회복지시설에 의해 아동과 가정에 전달되고, 각 시설은 중앙 부처와 각 지방자치 단체의 사업 운영 지침에 따라 관리하고 서비스를 제공하고 있다.

세부 사업의 서비스 전달체계로는 보육 및 양육에 관한 서

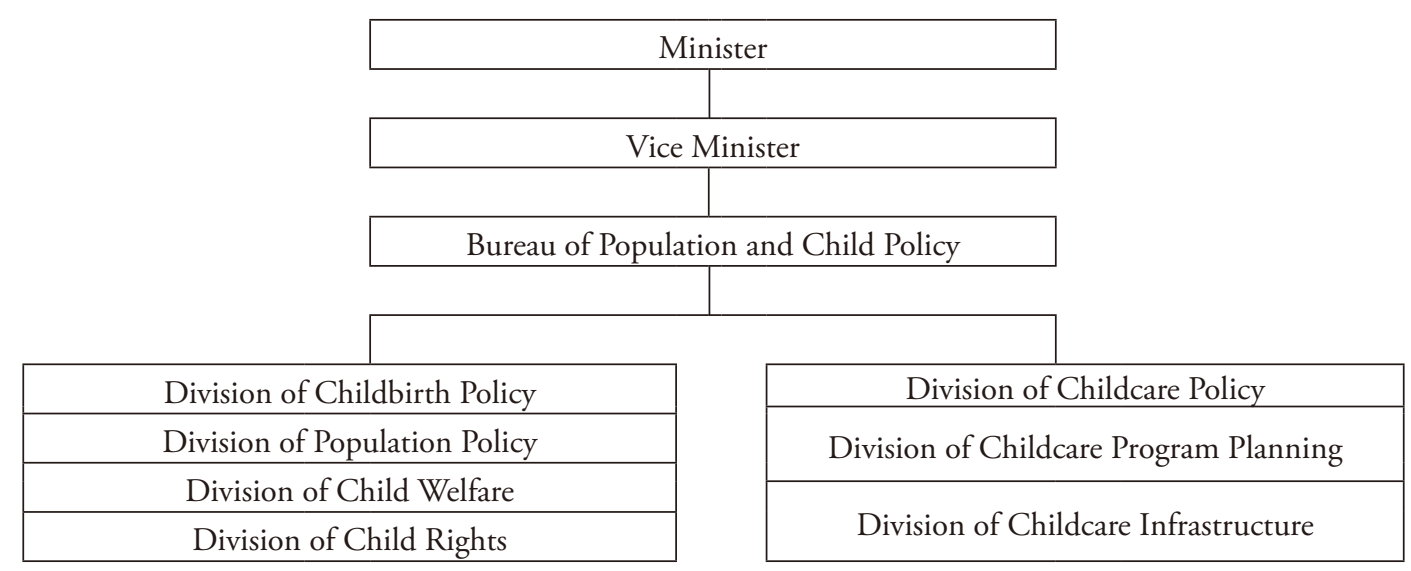

Figure 1. Organization chart of the Ministry of Health and Welfare for child policy. Adapted from the homepage of the Ministry of Health and Welfare (n.d.). 


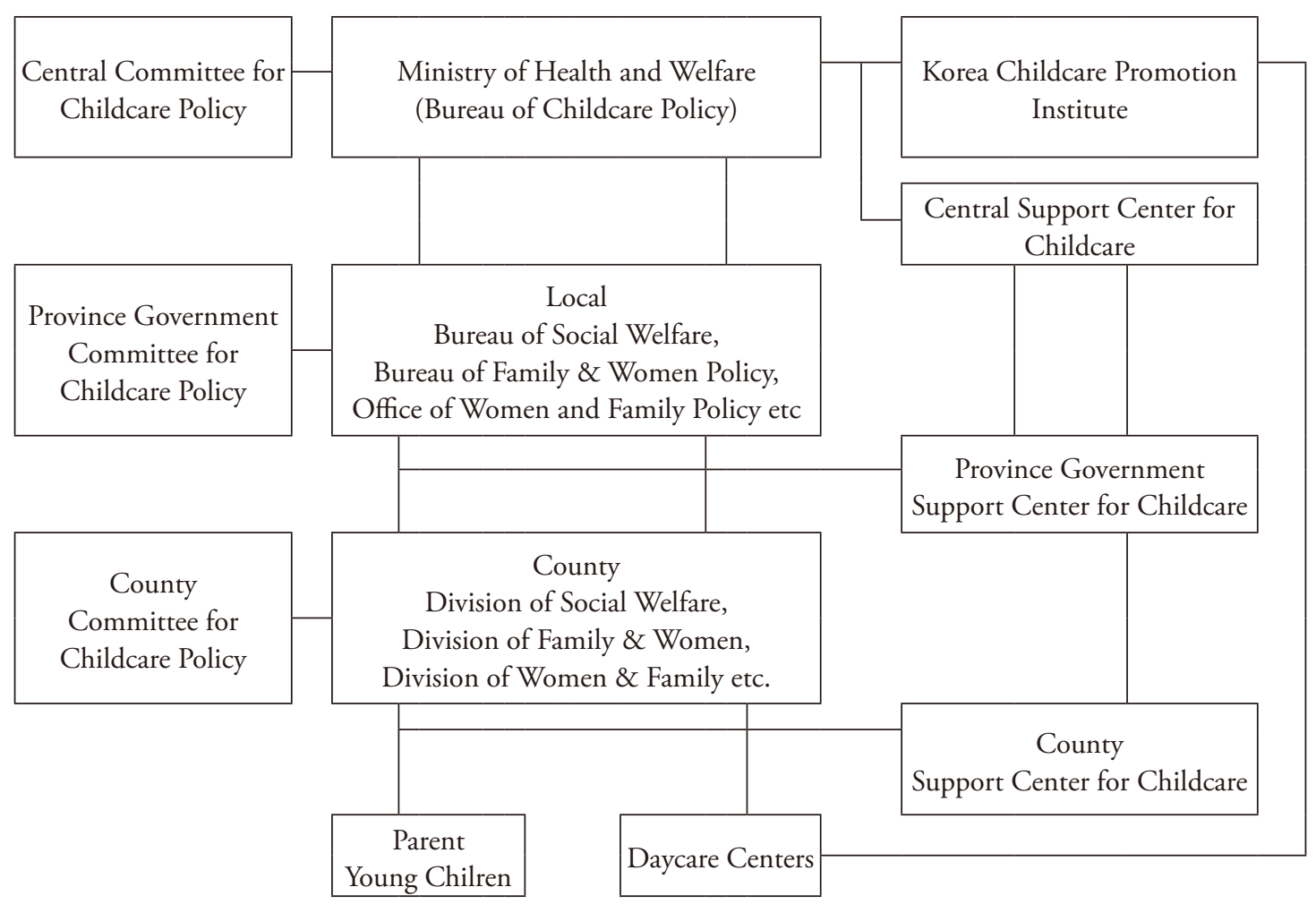

Figure 2. Administrative system for childcare service. Solid lines represent direct links, and dotted lines represent independent links. Adapted from the homepage of Central Support Center for Childcare (n.d.).

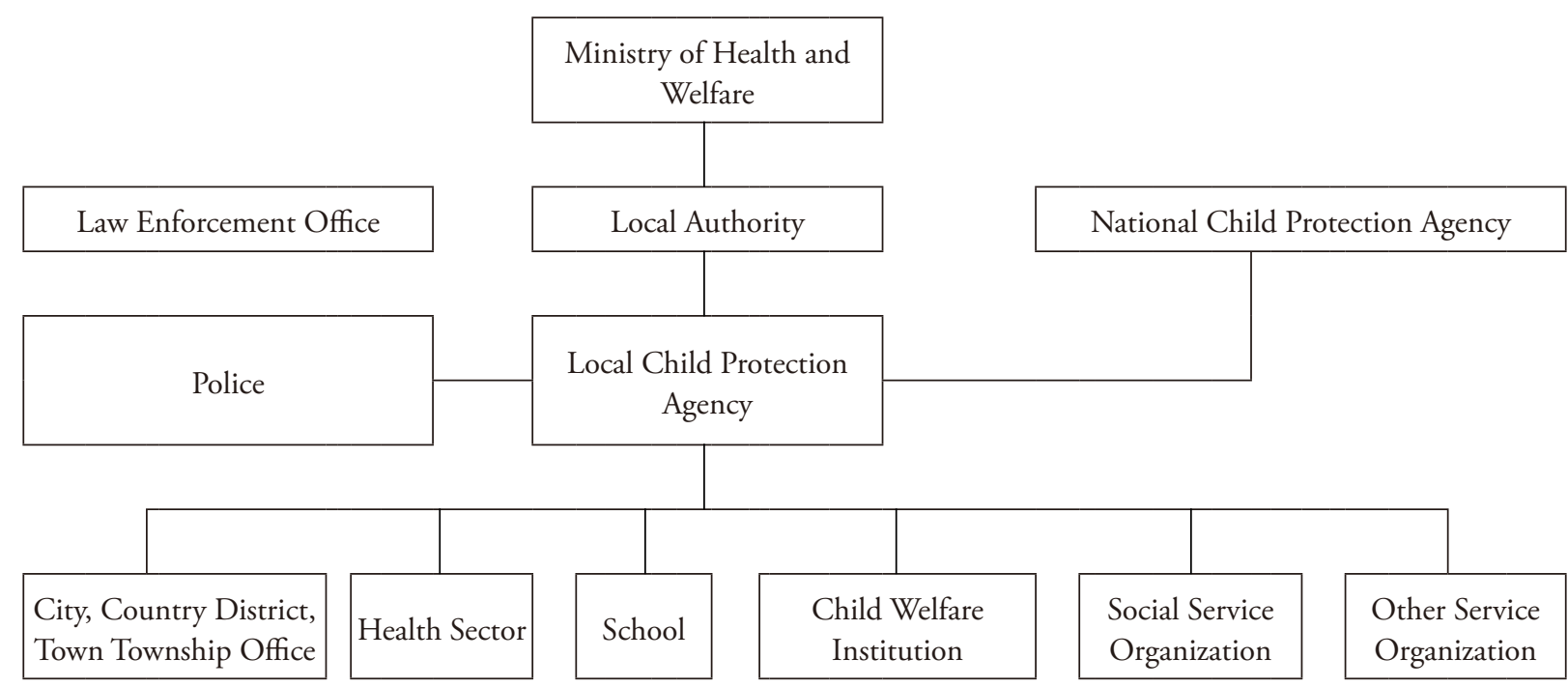

Figure 3. System of cooperating organizations for the prevention of child abuse and support of child abuse victims. Adapted from the homepage of the National Child Protection Agency (n.d.).

비스와 아동학대 관련 사업의 전달체계가 대표적이다. 먼저 보육 및 양육에 관한 서비스 전달체계는 영유아보육법에 근 거하여 보건복지부 보육정책관을 중심으로 중앙보육정책위 원회와 한국보육진흥원이 위탁 운영하는 중앙육아종합지원
센터를 통해 하위 단위로 각종의 서비스가 부모와 영유아 및 어린이집으로 전달되고 있다(Figure 2). 육아종합지원센터는 2016년 현재 전국적으로 중앙센터 1곳, 광역시·도 단위 센터 18 개, 시·군 · 구 단위 센터 71 개소의 총 90 개소가 운영되고 


\begin{tabular}{|c|}
\hline \multicolumn{2}{|c|}{ Minister } \\
\hline \multicolumn{2}{|c|}{ Vice Minister } \\
\hline Youth and Family Policy Office \\
\hline \multicolumn{2}{|c|}{ Youth Policy Bureau } \\
\hline \\
\hline Youth Policy Division \\
\hline Division of Youth Activities Promotions \\
\hline Youth Activities Safety Division \\
\hline Youth Self-Support Assistance Division \\
\hline Out-of-School Youth Support Division \\
\hline Division of Youth Protection Environment \\
\hline
\end{tabular}

Figure 4. Organization chart of the Ministry of Gender Equality and Family. Adapted from the homepage of the Ministry of Gender Equality and Family (n.d.).

있다. 육아종합지원센터는 어린이집에 대한 보육컨설팅, 교직 원 상담 및 교육 등 어린이집 지원 외에 부모에 대한 상담 및 교육, 열린어린이집, 부모모니터링단, 일시보육서비스 등 가 정양육지원서비스 등을 제공하고 있다.

다음으로 아동학대와 관련된 전달체계로는 아동복지법에 근거하여 보건복지부의 아동권리과 산하에 중앙아동보호전
문기관에서 업무를 담당하고 있다(Figure 3). 중앙아동보호전 문기관은 지역아동보호전문기관을 지원하고, 아동학대예방 사업 연구 및 자료 발간, 효율적인 아동학대예방사업을 위한 연계체계 구축, 아동학대예방 프로그램 개발 및 평가, 상담원 직무교육 및 아동학대예방관련 교육 및 홍보, 아동보호전문기 관 전산시스템 구축 및 운영 등의 업무를 수행하고 있다.

그 외에도 실종아동법에 근거하여 한국어린이재단이 보건 복지부로부터 실종아동전문기관을 수탁 받아 실종아동 등의 보호 및 지원 사업을 수행하고 있다.

\section{청소년정책서비스 전달체계}

청소년정책서비스는 여성가족부 청소년가족정책실에 청소년 정책관을 중심으로 전달체계를 구성하고 있다(Figure 4). 청소 년정책관은 청소년정책과, 청소년활등진흥과, 청소년활동안 전과, 청소년자립지원과, 청소년보호환경과, 학교밖청소년지 원과 등의 6개과로 조직, 운영되고 있다.

Lee, Cho, Khil과 Kim (2014, p. 385)에 의하면 지방 청소년 정책은 여성가족부의 청소년가족정책실로부터 행정자치부 산하의 시·도 및 시·군·구를 거쳐 읍·면·동으로 이어지는 전 달체계를 가지나, 지방으로 갈수록 청소년정책과 기타 정책 과의 구분은 사실상 모호해진다고 하였다. 즉, 중앙부처 중 어 떤 부서가 청소년정책을 기획했다할지라도 시·도에서는 행

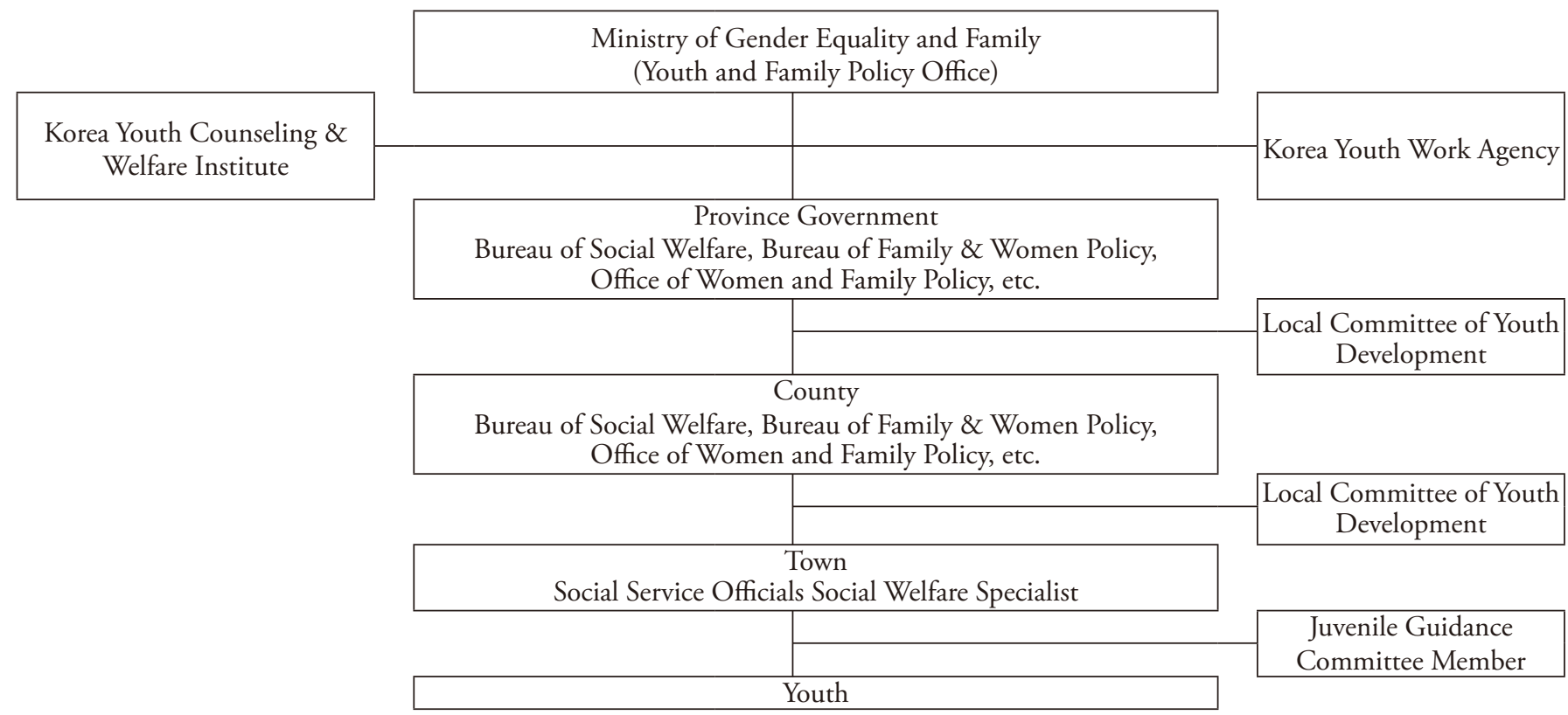

Figure 5. Administrative system for youth policy. Adapted form The introduction of youthology (p. 387), by M. R. Lee, S. Cho, E. B. Khil, and M. Kim, 2014. 
정자치부의 감독을 받는 사회복지국이나 가족여성정책국, 시·군·구의 경우에는 사회복지과나 가족여성과로, 읍.면·동 에서는 사회복지전문요원이나 사회담당공무원으로 일원화 된다. 광역자치단체의 시-도 사회복지국은 지방청소년육성위 원회의 운영에 관한 업무를 담당하면서 지방 청소년업무를 총 괄 - 조정한다. 시·군·구의 가족여성과는 청소년정책의 서비 스 대상자인 청소년에게 직접적 서비스를 제공하는 역할과 청 소년관련 시설에 대한 지원업무를 수행한다.

\section{정책 제언 및 아동학의 역할}

2015년 아동정책기본계획이 발표되기 전까지 아동정책은 1994년에 보육시설확충 3개년계획, 2002년에 어린이보호육 성종합대책, 2003년에 어린이안전종합대책, 2004년에 빈곤아 동청소년종합대책, 2008년에 아동청소년정책 5개년 기본계 획, 2013년에 유아교육발전기본계획 등 연령에 따라 특정분 야에 맞춰 다양하게 수립, 시행되어왔다. 즉, 아동복지법상의 아동 연령을 포괄하는 종합적이고 장기적인 정책이 부재했고, 이를 시행하는 주무부처도 보건복지부, 여성가족부, 교육부 등으로 산재해있어 부처 간 협조체제도 이루어지지 않아 산 발적으로 정책을 입안하여 수행해 왔다. 그 사이 2008년 아동 과 청소년을 아우르는 아동.청소년정책 5 개년 기본계획을 수 립하여 시행하기도 하였으나 중앙정부의 업무 분장으로 인해 2010년 아동과 청소년정책은 보건복지부와 여성가족부로 다 시 이원화되었다.

아동정책은 유엔아동권리협약에서 명시하고 있는 바와 같 이 아동에게 최선의 이익을 줄 수 있어야 한다. 이를 위해 국가 는 아동에게 우리사회의 온전한 시민으로서의 지위를 부여해 주어야 하며, 이를 통해 아동권리에 기반을 둔 아동정책을 수 립하여 실시해야 한다(Hwang, 2016). 그러나 현재 우리나라의 아동정책은 시행 부처가 다양하여 청소년정책과 별개로 입안 되고 시행되고 있어 해결해야 할 과제가 많다. 따라서 현행 아 동정책의 문제점을 고찰하면서 향후 보다 발전적인 아동정책 의 입안과 시행을 위한 제언을 하면 다음과 같다.

첫째, 현행 법령에서 정의하는 아동과 청소년의 연령이 상 이하여 이를 기초로 한 기본계획에서의 적용대상에 혼선을 초 래하고 있다. 아동정책기본계획에서의 대상은 아동복지법상 의 아동으로 18 세 미만의 자이고, 청소년 기본법, 청소년활동 진흥법, 청소년복지 지원법, 학교 밖 청소년 지원에 관한 법률 상의 청소년은 9-24세이고, 청소년 보호법과 아동· 청소년의
성보호에 관한 법률상의 청소년은 19세 미만이며, 민법상의 미성년은 19세 미만, 근로기준법상의 소년은 15-18세 미만이 다. 이처럼 사용하는 아동과 청소년의 용어는 동일하나 법률 을 적용하는 대상연령이 상이하여 정책을 입안하여 실행하는 데 있어 어려움이 있다. 따라서 아동정책을 실행함에 있어 그 대상 연령은 국제기준에 맞출 수 있도록 최소한 유엔아동권리 협약에서 제안하고 있는 18세 미만의 자가 모두 포함될 수 있 어야 할 것이다. 이를 위해 아동과 청소년을 모두 포괄하는 아 동기본법의 법령 제정이 우선되어야 할 것이며, 이를 통한 기 본정책의 입안과 실행이 필요하다.

둘째, 아동정책 기본계획의 총 예산을 4.5 조로 책정하고 있 으나 이에 대한 예산 확충방안의 마련이 불분명한 실정이다. 또한, 예산을 집행하는 지방자치단체별 재정자립도 수준도 상 이하여 기본계획을 실행함에 있어 지역 간 불균형이 나타날 수 있다. 따라서 균등한 아동의 삶의 만족도를 유지하기 위해 서는 중앙정부의 형평성을 고려한 지자체별 차등 예산지원과 이의 실행방안을 모색해야만 한다.

셋째, 아동정책기본계획 상의 추진과제를 수행할 소관부 처가 보건복지부, 여성가족부, 교육부, 문화체육관광부, 고용 노동부, 법무부, 미래창조과학부, 국토부, 국민안전처, 법무 부, 행정자치부(경찰청), 국가인권위원회 등으로 매우 다양하 여 이들 간의 협력체계를 효과적으로 유지할 수 있는 방안을 모색해야만 한다. 이를 위해서는 아동과 청소년정책을 하나의 통합된 부처에서 기본계획을 수립하고 시행할 수 있도록 보 건복지부와 여성가족부로 분리되어 있는 업무를 통합하여 아 동, 청소년, 가족 그리고 지역사회 관련 사업을 포괄할 수 있는 통합된 부처가 필요하다. 이와 관련하여 독일 정부는 아동 및 청소년정책을 수행하는 중앙부처로 가족·노인·여성·청소년 부를 두고 있다. 청소년부에서 아동 및 청소년 관련 업무를 총 괄적으로 담당하고 있다. 독일은 아동정책이나 청소년정책을 여성정책 및 가족정책과 연관시켜 생애주기적인 관점에서 정 책을 수립하여 실행하고 있다. 또한, 영국은 2003년에 발표한 "Every Child Matters"를 통해 0-19세 아동과 청소년을 위한 통 합개혁안을 실시하고 있다. 이를 위해 아동법(Child Act)과 아 동보육법(Childcare Act)를 개정하였고, 이를 통해 2006년에는 아동과 청소년을 위한 계획(Children and Young People's Plan) 을 마련하기도 하였다. 이를 위해 2007년에 중앙부처로 아동, 학교, 가족부(Department of Children, Schools and Families)를 두어 운영하다가 최근 이를 교육부(Department of Education) 로 명칭을 변경하고 관련 업무를 담당하고 있다. 영국도 독일 과 마찬가지로 아동과 청소년 정책을 가족과 연계하여 진행하 
고 있으며, 2006년부터 아동과 청소년을 위한 계획(Children and Young People's Plan)을 수립하여 진행하고 있다(MOGEF, 2015, p. 30). 이들 국가의 일관성 있는 정책수행과 비교할 때, 우리나라의 경우 아동 또는 청소년 기본계획을 실행하는 담당 공무원의 업무변경이 잦고, 이로 인해 업무수행의 일관성과 연속성이 결여되는 문제가 있다(Lee et al., 2014, p. 387). 그러 므로 여타 국가와 같이 아동과 청소년 업무를 전담하여 전문 화할 수 있는 부서의 확보와 안정된 인력의 수급이 필요하다.

넷째, 아동정책기본계획을 실행하는 동안 이를 모니터링하 고 평가할 수 있는 시스템이 부재하다. Rhu (2016) 아동정책 기본계획이 실효성을 거두기 위해서는 중앙부처와 지방자치 단체가 아동정책 시행의 책임주체로서 역할을 분명히 하는 것 이 필요하다고 지적하였다. 즉, 거시적 차원의 아동정책 종합 계획 그뿐만 아니라 아동의 다양한 이해와 요구를 지역의 특 수성에 맞게 반영하기 위해서는 지역사회 차원의 미시적 정 책과 이의 사업추진이 필수적이다. 그러나 현재 지역사회 중 심의 정책추진체계의 역량이 부족하고 아동정책 실행력의 지 역적 편차가 크다. 따라서 아동정책기본계획의 시행동안의 모니터링은 아동정책 추진역량이 취약한 지방자치단체에 대 한 중앙 정부의 지원과 컨설팅에 두어야 한다. 지방자치단체 의 아동정책기본계획 이행역량을 강화하기 위해서는 중장기 적으로 아동정책의 추진체계를 읍·면·동 수준으로 확대해나 가야 하며, 이를 위한 재정적-행정적 지원을 강화해야 할 것 이다. 이와 관련하여 영국의 교육표준청(Office for Standards in Education)과 같은 기구를 설립하여 아동과 청소년 서비스에 대한 조정과 평가를 담당하도록 하는 것도 필요할 것이다. 즉, 영국의 교육표준청은 단순히 교육만이 아니라 보다 포괄적으 로 아동과 청소년의 발달에 기여하는 기관을 평가하고 있고, 가정과의 연계 등도 강조하는 특징이 있다. 따라서 우리나라 도 아동정책기본계획이 수립되었으므로 이와 같은 기관을 벤 치마킹함으로써 보다 안정적으로 아동관련 정책을 정착시켜 실행할 수 있는 방안을 마련해야만 한다.

다섯째, 아동정책기본계획을 실행함에 있어 아동학 전문가 의 역할이 부재하였다. 아동학 전공자는 아동의 삶의 만족도 와 행복 수준을 향상시켜줄 아동정책 이행에 필요한 기본 교 과목을 이수한 전문가이다. 즉 아동기 역량 강화, 꿈과 끼를 살 리는 교육 실현, 아동의 참여권 보장, 놀이·여가 권리 보장으 로 아동결핍수준(정기적 여가활동 결핍)을 낮추고, 공동체 의 식을 함양하는데 필요한 지식과 기술을 겸비한 인적자원이 다. 그러므로 아동학 전공자를 인적 자원으로 활용할 수 있도 록 다양한 역할 개발이 이루어져야 한다. 또한 아동에 대한 기
본 지식과 배경을 갖춘 전문가로서 아동정책기본계획을 모니 터링할 수 있는 체제를 마련하는 과정에도 적극적으로 참여할 필요가 있다. 나아가 아동학 유관 기관과 학-협회의 연대를 통 해 아동권리 실현기반 조성, 민간과의 협력 강화, 아동정책지 원 인프라 강화를 위한 실행기반을 마련하는 과정에도 전문적 인 역할로 참여하여야 한다.

여섯째, 아동과 청소년관련법이 급변하는 환경에 빠르게 적응하지 못하여 적기에 필요한 정책을 입안하여 시행하는데 어려움이 있다. 이를 위해서는 기본 법률에는 최소한의 이념 이나 취지 등만을 명시하고 비교적 개정이 용이한 시행령과 시행규칙에 세분화하여 관련 내용을 명시하는 형태로 법체계 를 수정할 필요가 있다.

일곱째, 아동정책기본계획 상에 가정의 양육역량을 강화 하고 아동친화적 지역사회 조성을 실행기반으로 설정하고 있 으므로 영유아보육과 일·가정양립을 위한 통합된 양육지원 정책의 마련이 필요하다. 이를 위해 아동정책기본계획에 영 유아보육법상 명기되어 있는 아동의 최우선의 행복권 추구에 따라 부모와 자녀가 함께 할 수 있는 정책이 우선되어야만 한 다. 아동양육의 기초인 부모의 일·가정양립을 위한 기본계획 은 저출산.고령사회 기본계획, 건강가정기본계획 등에 별도로 마련하고 있어 아동정책기본계획과 별도로 운영될 소지가 많 다. 따라서 종합적인 아동정책을 수행하기 위해서는 여러 부 처의 기본계획을 통합하여 포괄적인 아동정책이 입안되고 수 립될 수 있어야 할 것이다. 이러한 정책의 수행을 위해서는 아 동가족을 위한 통합적인 서비스 사업 담당 부서가 새롭게 마 련될 필요가 있다. 한국의 부모는 자녀와 함께하는 놀이 및 교 육시간(2013년 기준)이 총 48 분(어머니 40 분, 아버지 8 분)으로 $\mathrm{OECD} 22$ 개국 평균 151 분의 $1 / 3$ 수준에도 미치지 못하는 최하 위 수준이다(OECD, 2015). 그러므로 아동정책기본계획에서 제시한 아동권리별과 발달환경별 정책과제가 제대로 수행될 수 있도록 보다 적극적인 중앙과 지방자치단체의 노력과 부모 역량강화와 더불어 아동의 행복추구권과 발달권을 보장해줄 수 있는 정책의 실행이 필요하다. 이를 위해 효과적인 영유아 정책을 실행할 수 있는 현행 여성가족부 산하의 건강가정지원 센터와 보건복지부 산하의 육아종합지원센터를 통합하고 이 에 따른 전달체계를 정비하여 운영할 필요가 있다.

이상의 정책제언과 관련하여 아동과 청소년을 포괄하여 연 구하고 실제 현장을 모니터링하는 아동학 분야는 현행의 아동 정책기본계획과 청소년기본계획에 대한 깊이 있는 이해를 통 해 다양한 역할을 수행해야만 한다.

무엇보다 아동학은 제 1 차 아동정책기본계획의 올바른 시 
행을 위해 보다 적극적으로 모니터링할 수 있는 시스템의 도 입을 위한 연구, 개발에 힘써야 할 것이다. 현재 아동정책기본 계획은 예산을 수립하고는 있으나 이의 확보방안이 충실하게 마련되어 있지 않고, 지방자치단체별로 그 재정자립도 수준도 다양하기 때문에 아동의 발달권과 생존권 및 보호권을 확보할 수 있는 방안의 마련이 필요하다. 따라서 아동학은 이의 확보 를 위해 과학적이고 객관적인 모니터링 지표를 개발하여 활용 할 수 있는 방안의 마련을 위한 노력을 경주해야만 한다. 과거 아동학은 연구중심의 학문적 수준에 머물러 있었지만 저출산 이 사회문제가 되고 있는 현 상황에서 아동의 권익을 신장하 고 확보할 수 있는 실제적 차원의 보다 적극적인 활동이 필요 하다. 특히 아동학은 가족 속에서의 아동의 전인적인 발달에 초점을 맞추고 있으므로 아동이 보다 안전하고 건강하게 가족 과 함께 미래를 준비할 수 있는 삶을 살 수 있도록 다양한 측면 에서 정책제언을 하고, 그 효과성을 검증할 수 있도록 법과 제 도 개선을 위해 보다 적극적인 노력을 경주해야만 할 것이다.

둘째, 아동을 대상으로 서비스를 제공해주는 성인에 대한 처우도 아동학에서 보다 많은 관심을 가지고 그 개선을 위해 노력해야 할 것이다. 즉, 일-가정 양립을 위한 부모를 포함하 여 영유아와 아동과 직접 상호작용하는 유치원교사와 보육교 사 및 각급 학교 교사 및 일선 전달체계에서 활동하는 사회복 지사와 청소년지도사 및 교육복지사의 처우 개선과 지위 향상 을 위해 아동학은 보다 주의 깊은 관심을 가지고 노력해야 할 것이다. 공무원으로서 사회복지전담공무원은 이미 법체제에 서 그 지위가 확보되어 있으나 교육복지사나 다수의 보육교 사, 유치원 교사에 대한 지위 확보와 사회적 인식 제고 및 처우 개선과 근무 시간 등에 대한 개선 등을 위해서는 아동학의 제 분야에서 보다 적극적인 역할을 수행할 수 있는 방안을 모색 해야만 할 것이다. 교육복지사는 무기직으로 전환되어 과거에 비해 지위 불안에 대한 요소는 상당 부분 해소되었으나 교육 이라는 체제 속에서 교사가 아닌 신분으로 학교에서 활동하고 있어 여전히 충분한 대우를 받지 못하는 경우가 많으므로 이 를 개선하기 위한 노력도 필요하다. 또한, 보육교사는 유치원 교사에 비해 그 지위를 더 낮게 보는 사회적 인식에 대한 부분 도 개선이 필요하다. 그뿐만 아니라 아동학의 진로와 관련하 여 아동정책기본계획을 수행하는 관련 분야 중 부모교육 활성 화와 관련하여 다양한 연령계층과 가족유형에 적합한 부모교 육 프로그램의 개발을 위한 노력을 경주하고, 전국적으로 확 대하여 실시할 수 있는 정책 제안과 노력을 보다 적극적으로 모색해보아야만 할 것이다.

셋째, 대학의 교육과정을 보다 현실적으로 개편하여 아동
학의 지평을 확대해나갈 수 있는 방안을 모색해야 할 것이다. 현재의 아동학관련 분야의 교육과정은 유아교육이나 보육교 사 양성을 위한 것에 상당 부분 편향되어 있는 경향이 있으므 로 다양한 가족에 적합한 정책이나 제도에 대한 이해나 생태 학적 맥락에서의 아동학분야 확대 적용을 위한 교육과정 개편 노력이 필요하다. 또한, 아동학과 청소년학이 별도로 개설, 운 영됨에 따라 마치 아동학과 청소년학이 별개의 학문인 것처럼 받아들여지고 있으므로 이를 통합하여 운영하거나 연계하여 운영할 수 있는 포괄적인 교육과정의 개편을 위한 노력도 필 요하다.

넷째, 아동학과와 청소년학과가 유기적인 협력관계를 모색 할 수 있도록 자격증 취득을 연계할 수 있는 방안을 모색하려 는 노력을 경주해야 할 것이다. 현재 생애주기적인 관점에서 의 인간발달을 고려하는 학문적 관심이 높아져가고 있으므로 아동학에서의 자격증 취득과정을 현행 청소년학분야의 자격 증 취득과 연계할 수 있는 방안을 고려해보아야 할 것이다.

이상으로 향후 아동학분야에서는 아동복지법과 청소년 기 본법에서 명시하고 있는 복지대상자의 요구에 부합되도록 기 본계획 수립 및 이의 실행에 필요한 정책 제안과 모니터링할 수 있는 방안 마련에 노력을 경주해야 할 것이다. 나아가 실수 요자의 요구가 반영될 수 있도록 관련 법 개정에도 관심을 기 울여야 할 것이다.

\section{Notes}

This article was presented as a poster at the 2016 Annual Spring Conference of the Korean Association of Child Studies.

\section{Conflict of Interest}

No potential conflict of interest relevant to this article was reported.

\section{References}

\section{In English}

Organisation for Economic Co-operation and Development. (2015). How's life? 2015: Measuring well-being. Paris: 
OECD. doi:10.1787/how_life-2015-en

\section{In Korean}

Act on Prevention of Child Poverty, support of children, Act No. 14172, 2016. Retrieved from http://www.law.go.kr/

Act on the Protection and Support of Missing Children, Act No. 12844, 2014. Retrieved from http://www.law.go.kr/

Act on special cases concerning the Punishment of Child Abuse Crimes, Act No. 12844, 2014. Retrieved from http://www. law.go.kr/

Central Support Center for Childcare. (n.d.). Administrative system [Web page]. Retrieved from http://central. childcare.go.kr/

Child Welfare Act, Act No. 14058, 2016. Retrieved from http:// www.law.go.kr/

Framework on Juveniles, Act No. 14066, 2016. Retrieved from http://www.law.go.kr/

Hwang, O. K. (2016). The second chance: The child policy based on child rights. Health and Welfare Policy Forum, 233, 2-4. Retrieved from http://www.kihasa.re.kr/

Hwang, S.-H. (2010). Juristical understanding of basic law system focused on legal issues in the integration: Separation argument of children and youths fields. Public Law Journal, 11(1), 243-270. Retrieved from http://www.riss.kr/ link?id=A82259716

Infant Care Act, Act No. 14001, 2016. Retrieved from http://www. law.go.kr/

Juvenile Activity Promotion Act, Act No. 14068, 2016. Retrieved from http://www.law.go.kr/

Juveniles Protect Act, Act No. 13726, 2016. Retrieved from http:// www.law.go.kr/

Juvenile Welfare Support Act, Act No. 14237, 2016. Retrieved from http://www.law.go.kr/

Korean Foundation of Banjeongwhan, Institute for Social
Development Studies. (2016). The $8^{\text {th }}$ Korean child $\cdot$ youth happiness index. Retrieved from http://www.korsofa.org/

Lee, M. R., Cho, S., Khil, E. B., \& Kim, M. (2014). The introduction of youthology. Seoul: Hakjisa.

Ministry of Gender Equality and Family. (n.d.). Organization chart [Web page]. Retrieved from http://www.mogef.go.kr

Ministry of Gender Equality and Family. (2012). The fifth master plan of Korean youth (2013-2017). Retrieved from http:// www.mogef.go.kr/

Ministry of Gender Equality and Family. (2015). 2015 youth white paper. Retrieved from http://www.mogef.go.kr/

Ministry of Health and Welfare. (n.d.). Organization chart [Web page]. Retrieved from http://www.mohw.go.kr/

Ministry of Health and Welfare. (2015). The changes of children's life and the future of Korea: The first master plan of Korean children ('15-'19). Retrieved from http://129.go.kr

National Child Protection Agency. (n.d.). About us [Web page]. Retrieved from http://korea1391.go.kr/

Rhu, J. H. (2016). The significance and role of the first master plan for child policy. Health and Welfare Policy Forum, 233, 6-18. Retieved from https://www.kihasa.re.kr/

\section{ORCID}

Songyon Cho

Eun Bae Khil

Hye Yeong Choi http://orcid.org/0000-0001-7451-5734

http://orcid.org/0000-0001-8514-3606

http://orcid.org/0000-0002-1976-7178
Received October 31, 2016 Revision received November 30, 2016

Accepted December 13, 2016 